\title{
HDL-C: Does it matter? An update on novel HDL-directed pharmaco-therapeutic strategies.
}

\author{
Ramprasad Gadi \\ Einstein Medical Center and Jefferson Medical College \\ Aman Amanullah \\ Einstein Medical Center and Jefferson Medical College \\ Vincent M. Figueredo \\ Einstein Medical Center and Jefferson Medical College
}

Follow this and additional works at: https://jdc.jefferson.edu/cardiologyfp

Part of the Cardiology Commons

Let us know how access to this document benefits you

\section{Recommended Citation}

Gadi, Ramprasad; Amanullah, Aman; and Figueredo, Vincent M., "HDL-C: Does it matter? An update on novel HDL-directed pharmaco-therapeutic strategies." (2013). Division of Cardiology Faculty Papers. Paper 33.

https://jdc.jefferson.edu/cardiologyfp/33

This Article is brought to you for free and open access by the Jefferson Digital Commons. The Jefferson Digital Commons is a service of Thomas Jefferson University's Center for Teaching and Learning (CTL). The Commons is a showcase for Jefferson books and journals, peer-reviewed scholarly publications, unique historical collections from the University archives, and teaching tools. The Jefferson Digital Commons allows researchers and interested readers anywhere in the world to learn about and keep up to date with Jefferson scholarship. This article has been accepted for inclusion in Division of Cardiology Faculty Papers by an authorized administrator of the Jefferson Digital Commons. For more information, please contact: JeffersonDigitalCommons@jefferson.edu. 


\title{
HDL-C: DOES IT MATTER? \\ An update on novel HDL- directed
}

\section{pharmaco-therapeutic strategies}

\author{
Ramprasad Gadi, MD, ABCL \\ Aman Amanullah, MD PhD \\ Vincent M. Figueredo, MD
}
Einstein Institute for Heart and Vascular Health, Albert Einstein Medical
Center, and Jefferson Medical College, Philadelphia, PA

Running head: High density lipoprotein (HDL-C) and cardiovascular disease

Key words: high density lipoprotein (HDL-C), HDL-C therapeutics, cardiovascular, coronary artery disease

Disclosures: no conflict of interest

Address correspondence to: Dr.Ramprasad Gadi, MD

Einstein Institute for Heart and Vascular Health

5501 Old York Road, Levy 3

Philadelphia, PA 19141

TEL: 215-431-9404

FAX: 215-405-3781

E-mail: ram.gadi@gmail.com 
HDL THERAPEUTICS ABSTRACT

It has long been recognized that elevated levels of low-density lipoprotein cholesterol (LDL-C) increase the risk of cardiovascular disease (CHD) and that pharmacologic therapy to decrease LDL-C significantly reduces cardiovascular events. Despite the effectiveness of statins for CHD risk reduction, even optimal LDL-lowering therapy alone fails to avert $60 \%$ to $70 \%$ of $\mathrm{CHD}$ cases. A low plasma concentration of high-density lipoprotein cholesterol (HDL-C) is also associated with increased risk of CHD. However, the convincing epidemiologic data linking HDL cholesterol (HDL-C) to CHD risk in an inverse correlation has not yet translated into clinical trial evidence supporting linearity between HDL-C increases and CHD risk reduction. It is becoming clear that a functional HDL is a more desirable target than simply increasing HDL-C levels. Discoveries in the past decade have shed light on the complex metabolic and antiatherosclerotic pathways of HDL. These insights, in turn, have fueled the development of new HDL-targeted drugs, which can be classified according to four different therapeutic approaches: directly augmenting the concentration of apolipoprotein A-I (apo A-I), the major protein constituent of HDL; indirectly augmenting the concentration of apo A-I and HDL cholesterol; mimicking the functionality of apo A-I and enhancing reverse cholesterol transport. This review discusses the latest in novel HDL directed therapeutic strategies. 
TOPIC: HDL C - Does it matter?

An update on novel HDL-C directed therapeutic strategies INTRODUCTION:

An estimated 16.3 million persons, or $7.6 \%$ of the United States population, have

coronary heart disease (CHD) (1). Cardiovascular disease is responsible for 811,940

or $32.8 \%$ of all deaths in the United States on an annual basis (1). Focused risk

reduction therapies are indicated for patients with $\mathrm{CHD}$ and those at significant risk to

reduce events and improve survival rates.

The relationship between low density lipoprotein cholesterol (LDL-C) and high density

lipoprotein cholesterol (HDL-C) and the development of CHD is widely acknowledged.

In addition, the cardiovascular benefit for lowering LDL-C for those with CHD is now

well established (2). Current treatment strategies for reducing CHD risk are insufficient

to prevent most CHD events and suggest therapies for increasing $\mathrm{HDL}-\mathrm{C}$ in addition to

reducing LDL-C are necessary to prevent CHD events (3-5). 
However, the convincing epidemiologic data linking HDL-C and CHD risk has not yet translated into significant clinical trial evidence supporting linearity between HDL-C increases and CHD risk reduction. The recent negative results obtained in the ILLUMINATE and AIM-HIGH trials suggest that HDL-C increases may not always be beneficial (41, 63). The results from these studies have led us to more questions than answers in our quest to reduce CHD events by improving HDL-C.

\section{HDL FUNCTION}

The knowledge of an inverse relationship between plasma levels of HDL-C and rates of CHD gained from epidemiological studies has long been held as a near guarantee that interventions that increase HDL-C will reduce $\mathrm{CHD}$ risk $(6,7)$. However, investigators in clinical trials have so far failed to convey a mandate to increase HDL-C levels by a specific degree or beyond a specific threshold to achieve protection against CHD events (8). Moreover, both genetic studies and clinical trials support the idea that, in some circumstances, HDL-C levels may behave opposite to what is predicted by the Framingham assessment model $(9,10)$. For example, carriers of the apoAl Milano mutation present with low levels of HDL-C but are resistant to atherosclerosis $(11,12)$, whereas subjects with cholesteryl ester transfer protein (CETP) deficiency have high HDL-C levels but are not patently 
protected against atherosclerosis(13-16). In addition, common polymorphisms in the CETP and hepatic lipase genes linked to elevated HDL-C levels are associated with increased cardiovascular events (17, 18).

These apparently contradictory findings may be explained by the notion that a "functional" HDL, rather than high plasma HDL-C concentration, is needed for a therapeutic effect. HDL functionality and HDL-C concentrations likely go hand in hand in most people, but may diverge in the presence of specific mutations, in some disease states, or by the action of drugs (19-21). Therefore, newer therapies need to target HDL functionality rather than only HDL-C concentrations in the blood.

Mutations affecting the function of an enzyme rarely are linked to improved metabolism or health. Polymorphisms of both the CETP gene, leading to high HDL-C levels through reduced cholesterol exchange, and the hepatic lipase gene, leading to high HDL-C levels through impaired lipolysis, have been linked to increased risk for $\operatorname{CHD}(17,18)$. Indeed, a dysfunctional HDL is more likely associated with high, rather than low, HDL-C levels because it may often reflect altered recycling of the mature plasma HDL particle. Because of its high concentration, carrying a dysfunctional HDL may be more dangerous for vascular 
health than having low levels of functional HDL. Ansell et al (22) showed that patients with CHD and HDL-C greater than $85 \mathrm{mg} / \mathrm{dL}$ carry dysfunctional HDL. A recent analysis of The Incremental Decrease in Endpoints through Aggressive Lipid Lowering trial (IDEAL) and European Prospective Investigation of Cancer-Norfolk observational study determined that the classic inverse correlation between HDL-C and CHD risk is not sustained when evaluating subjects with HDL greater than $70 \mathrm{mg} / \mathrm{dL}$ who appear to have increased CHD risk even when on statin therapy (23). CHD risk was also increased by the presence of large HDL particles, suggesting that dysfunctional reverse cholesterol transport with accumulation of lipid-loaded HDL in the plasma and high HDL-C levels is a pro-atherogenic condition (23). Thus it is becoming clear that a functional HDL is a more desirable target than simply increasing HDL-C levels.

A reason why so much emphasis is placed on the plasma HDL-C level as a predictor of vascular health is because it theoretically represents reverse cholesterol transport (RCT), the system in charge of removing cellular cholesterol excesses from tissue sites of accumulation (24). The sub endothelial space of the medium caliber artery is the most important tissue in this regard because accumulation of cholesterol-rich cells causes atheroma formation and the real target of therapy is to activate cholesterol exit 
from this very site. Because the essential function of HDL occurs in the extravascular space, and not in the plasma compartment, it is likely that plasma HDL-C levels have a limited power to predict RCT functionality in the target tissue. Moreover, HDL influences the atherogenic process not only through cholesterol extraction but also through anti-inflammatory and antioxidant properties (25).

However, what we test in plasma is almost exclusively the amount of cholesterol that the HDL has collected from tissues other than the arterial wall. If inappropriate amounts of HDL penetrate the plaque or if the load of oxidized plaque lipids destabilizes HDL function, it is obvious that plasma HDL-C levels may be more and more disconnected from CV risk prediction. This new knowledge on dysfunctional HDL has been termed a paradox because functionality is not directly linked to changes in HDL-C plasma concentrations (26). However, there is nothing paradoxical about it. RCT is necessary to remove excess cholesterol from peripheral cells in all tissues, a biologically essential function even if cholesterol trapping in the artery wall and the atherosclerotic process were not a common occurrence in humans. Plasma HDL-C levels represent the balance between generation of mature HDL particles in the circulation and loss of lipid cargo via both HDL receptor (scavenger receptor type BI [SR-BI])-mediated transfer to hepatocytes and CETP-mediated transfer to other lipoproteins. $(27,28)$ 
Loss of lipid cargo is a desirable event because it leads to unloading of cholesterol and oxidized phospholipids in the liver and to the rebirth of

the HDL particle for a new round of cholesterol acquisition. Therefore, a high HDL-C level may mean enhanced production of mature HDL in the plasma compartment (a good thing) or reduced loss of lipid cargo (not a good thing). Conversely, a low HDL-C level may signal increased loss of lipid cargo (a good thing) or reduced peripheral cholesterol collection (not a good thing).

\section{HDL METABOLISM}

HDL starts its life cycle as poorly lipidated apolipoprotein Al (apoAl), which has a mandate to collect cellular cholesterol to avoid receptor-mediated degradation in the renal tubule $(29,30)$ (see Fig 1 ). ApoAl collects membrane cholesterol through multiple mechanisms, including specific ones requiring physical engagement with transmembrane lipid channels such as ATP-binding cassette transporter A1 (ABCA1), ATP-binding cassette transporter G1 (ABCG1) and scavenger receptor class B member (SR-BI) (31). It is believed that ABCA1 transfers phospholipids and cholesterol to the nascent HDL (32), whereas ABCG1 connects with larger HDL particles (33). SR-BI (also known as the hepatic HDL receptor) contributes significantly to lipid transfer from cells overloaded with cholesterol, such as arterial 
macrophages, and therefore may play a central role in atherogenesis (34). As free (unesterified) cholesterol translocates across the cell membrane, HDL esterifies it by adding a fatty acid chain via the action of lecithin cholesterol acyl-transferase (LCAT) (31). The nonpolar cholesteryl esters are then stored in the particle core. The core expansion leads to compositional maturation, yielding particles that predominate in plasma HDL. This sequence of changes means that HDL is heterogeneous in size because of variations in total lipid cargo and in the array of lipoproteins, enzymes, and other functional proteins that can exist on its surface (35).

In the plasma compartment the mandate of the mature HDL switches from cholesterol acquisition to cholesterol delivery. This is achieved mainly via cholesteryl ester transfer protein (CETP)-mediated transfer of cholesterol to triglyceride-rich lipoproteins and via SR-BI mediated unloading of the cholesterol cargo in the liver. Plasma HDL that eliminates its lipid cargo can initiate a new cycle of peripheral cholesterol acquisition. This "reverse cholesterol transport-centric" view of HDL also encompasses the notion that its powerful anti-oxidant and anti-inflammatory effects are linked to the collection and removal of oxidized lipids from both cellular membranes and LDL in the arterial wall (36).

\section{NONPHARMACOLOGIC APPROACHES FOR RAISING HDL}


The National Cholesterol Education Program (NCEP) Adult Treatment Panel III (ATP III) increased the definition of low HDL cholesterol from $35 \mathrm{mg} / \mathrm{dl}$ to $40 \mathrm{mg} / \mathrm{dl}$ (37). Low HDL-C is also an important component of the definition for metabolic syndrome, with cut points of $40 \mathrm{mg} / \mathrm{dl}$ for men and $50 \mathrm{mg} / \mathrm{dl}$ for women. The NCEP ATP III guidelines state that therapeutic lifestyle changes are the initial intervention for increasing HDL cholesterol. These therapeutic lifestyle change measures include reducing the dietary intake of cholesterol, increasing the use of plant stanols/sterols and fiber to lower LDL cholesterol, and moderating intake of calories and increasing physical activity to maintain desirable weight and cardiovascular fitness. Weight loss and smoking cessation are also advocated and can aid in raising serum levels of HDL. Dietary modification, including ingestion of omega-3 fatty acids via fish consumption or fish oil supplementation, has also demonstrated an effect in raising HDL-C. When therapeutic lifestyle changes are not adequate to increase serum HDL-C, pharmacologic therapy is often recommended.

\section{PHARMACOLOGIC THERAPY}

When therapeutic lifestyle changes are not adequate to achieve target goals, several pharmacologic therapy options exist for the management of low HDL-C (Table 1). It is well established that 3-hydroxy-3-methylglutaryl coenzyme A (HMG-CoA) reductase 
inhibitors (statins) lower LDL-C, which significantly affects cardiovascular morbidity and mortality (2). Other non-LDL lipid effects of statins, including decreasing triglycerides and raising HDL-C, may also contribute to the risk reduction. Additional therapies with significant LDL lowering effects, such as fibrates and niacin, which lower triglycerides and raise $\mathrm{HDL}-\mathrm{C}$, also have been shown to reduce CHD events despite less potent effects on reducing LDL (38). As highlighted in the NCEP ATP III guidelines, consideration should be given to combination therapy with a fibrate or nicotinic acid in addition to a statin for high-risk patients with a low HDL-C level (see Fig 2).

\section{STATIN THERAPY}

First-line management of dyslipidemia in patients with cardiovascular disease is achieved with statin therapy. In patients with low HDL-C, statins are very effective in reducing the absolute cardiovascular event rate (2). However, the residual risk of CHD events remains high. Statins typically increase HDL-C levels by approximately $5 \%$ to $10 \%$. Although the mechanism(s) by which statins raise HDL-C remains unclear, statins appear to reduce the supranormal rates of endogenous CETP-mediated cholesteryl ester transfer from HDL by decreasing the number of Apo B lipoprotein available to accept cholesteryl ester from HDL. Statins also appear to enhance hepatic Apo Al production, which may not occur with high-dose atorvastatin $(80 \mathrm{mg})$ in which there is 
less HDL-C increase compared with similar LDL-C lowering by simvastatin or rosuvastatin. The clinical relevance of the difference in the HDL-C increase between atorvastatin $80 \mathrm{mg}$ and rosuvastatin 40 mg is being tested in the Study of Coronary Atheroma by Intravascular Ultrasound: Effect of Rosuvastatin Versus Atorvastatin (SATURN) trial, an intravascular ultrasound (IVUS) trial measuring plaque volume in CHD patients (39).

\section{NIACIN}

Niacin, or nicotinic acid, is a soluble B vitamin that has favorable effects on all major lipid sub fractions but has limited use due to its side-effect profile. Niacin was one of the first lipid-altering drugs to demonstrate a reduction in CHD events in the Coronary Drug Project (40). At present, niacin is identified as the most effective approved for raising HDL-C. In clinical studies, niacin has been demonstrated to lower LDL by $10 \%$ to $20 \%$, triglyceride (TG) by $20 \%$ to $40 \%$, and Lp (a) by $10 \%$ to $30 \%$, as well as raise HDL by $15 \%$ to $30 \%(40)$. Niacin appears to increase HDL-C by decreasing the hepatic uptake of Apo Al, thereby delaying catabolism (41). Despite niacin being widely used in the management of dyslipidemia, the side effect of flushing of the face and upper body can affect compliance to therapy. Flushing has been attributed as the major reason for discontinuation of therapy, estimated at rates as high as $25 \%$ to $40 \%$ The flushing that is induced 
by niacin is caused by the subcutaneous release of prostaglandin D2 (PGD2), which is mediated by niacin's action as a pharmacologic ligand for the adipocyte and macrophage $\mathrm{G}$ protein coupled nicotinic acid receptor, GPR109A (42). The cutaneous vasodilation skin flush typically starts in the face with a deep red coloration, usually accompanied by an intense feeling of warmth and itching, with occasional extension to the arms and chest. Although the duration of the flushing is generally less than 1 hour, the unpleasant sensation for patients can often affect compliance and lead to therapy discontinuation. Moderate doses of prostaglandin inhibitors have been demonstrated to reduce the cutaneous flushing response from niacin (43). Several additional strategies for reducing niacin induced flushing include regular consistent dosing, use of extended-release formulations, patient education, dosing with meals or at bedtime, and avoidance of alcohol, hot beverages, spicy foods, and hot baths or showers close to or after dosing. In comparison with immediate release niacin, extended-release niacin results in reduced flushing as it is taken once a day at bedtime, when most flushing symptoms will occur when the patient is sleeping. However, the side effect profile includes the potential for liver toxicity (44). Other side effects include rash, flushing, gastrointestinal problems, worsening of esophageal reflux and gout, and headache (44). 


\section{STATIN - NIACIN COMBINATION THERAPY}

Combination therapy with a statin and niacin has been used to reduce residual cardiovascular risk after statin use by targeting both the lowering of LDL-C and increasing low HDL-C. Several clinical trials using either immediate-release or extended-release niacin have demonstrated the efficacy and safety of this combination therapy in inhibiting the development of atherosclerosis (45). The Arterial Biology for the Investigation of the Treatment Effects of Reducing Cholesterol (ARBITER) 2 trial demonstrated that the addition of extended-release niacin to statin therapy resulted in an increase in HDL-C of $21 \%$ and slowed the progression of atherosclerosis as measured by a change in carotid intima-media thickness (CIMT), as compared with statin therapy alone in patients with known CHD and low HDL-C levels (45). Although the ARBITER 2 trial showed slowing of progression of atherosclerosis, whether this translates to reduction of CHD events remains unclear.

The Atherothrombosis Intervention in Metabolic Syndrome with Low HDL/High Triglycerides: Impact on Global Health (AIM-HIGH) trial was the first large-scale outcomes study to evaluate the impact of adding extended-release niacin to statin therapy (simvastatin) in patients with established coronary artery disease (46). The study was designed to 
test whether or not increasing HDL-C and lowering triglycerides in patients with low HDL-C and high triglycerides will reduce the risk of recurrent cardiovascular events in patients whose LDL-C was already within a desirable range with statin therapy.

AIM-HIGH enrolled 3414 participants in the US and Canada, who were all prescribed simvastatin and then randomized to either high-dose, extended-release niacin in gradually increasing doses up to $2000 \mathrm{mg}$ per day $(n=1718)$ or placebo $(n=1696)$. Of the participants, 515 were given a second LDL-cholesterol-lowering drug, ezetimibe (Zetia, Merck/Schering-Plough), in order to maintain LDL-cholesterol levels at the target range between 40 and $80 \mathrm{mg} / \mathrm{dL}$.

The primary end point for AIM-HIGH was a composite defined as time to first occurrence of any of the following: fatal or nonfatal myocardial infarction, ischemic strokes, hospitalizations for acute coronary syndrome or symptom driven coronary or cerebral revascularization procedures. Background therapy for all risk factors (blood pressure, blood glucose) was rigorous and met the goals set forth in the guidelines for high-risk patients. The addition of niacin to half of the patients did provide incremental HDL-C elevation and triglyceride reduction. However, the National Heart, Lung, and Blood Institute halted the trial prematurely because continuing was deemed futile after interim analyses showed no significant difference in adverse 
outcomes between the two groups (249 primary outcome events [15\%] in the simvastatin arm and 262 [15\%] in the simvastatin/niacin arm; hazard ratio $1.053,97.5 \% \mathrm{Cl}: 0.885-1.252 ; \mathrm{P}=0.561)$. Moreover, investigators observed an excess hazard for ischemic stroke (28 vs. 12 ) that was numerically, though not statistically, significant in the group receiving niacin. Because of the small difference between treatment arms and the early termination of the trial, AIM-HIGH was underpowered to prove the hypothesis that niacin therapy may be beneficial in a secondary prevention population with controlled LDL-C. Therefore, the results of the study cannot be extrapolated to all patients with low HDL or all patients with uncontrolled LDL. The findings of AIM-HIGH will require careful study to determine if there are specific reasons for the failure of niacin to provide incremental risk reduction in this population of patients. The entire question of emerging science related to modulation of HDL in blood plasma is still being evaluated as new therapies beyond niacin are being developed. Ongoing pharmaceutical outcomes studies such as HPS2-THRIVE with over 25,000 patients may provide more insight regarding the efficacy of niacin in combination with statins to reduce CHD events. The Heart Protection Study 2 Treatment of HDL to Reduce the Incidence of Vascular Events (HPS-2-THRIVE) is another large international trial of high-dose, extended-release niacin with simvastatin alone or in combination with ezetimibe in patients with 
established cardiovascular disease. The study is still ongoing, with results expected in 2013 (47)

\section{STATIN-FIBRATE COMBINATION THERAPY}

Statin-fibrate combination therapy is effective in reducing LDL-C and TG, and in increasing HDL-C. Fibrates are peroxisome proliferator-activated receptor-alpha (PPAR-a) ligands that lead to increased lipoprotein lipase expression and decreased Apo CIII expression. This results in enhanced catabolism of TG-rich particles. The expression of Apo Al and A-II are also increased by fibrates, with a net result of decreasing hypertriglyceridemia and increasing HDL-C. Due to these effects, fibrate combination therapy is used for patients with hypertriglyceridemia and low HDL. Statin- fibrate combination use is restricted, due to reports of rhabdomyolysis that mainly involved gemfibrozil and cerivastatin, which was voluntarily withdrawn from the market worldwide in 2001 after reports of fatal rhabdomyolysis.

Fenofibrate or fenofibric acid is the fibrate of choice when used in combination with a statin because each is associated with a lower risk of myopathy than gemfibrozil. Several recent studies have demonstrated the efficacy and safety of fenofibric acid and statin 
therapy in patients with mixed dyslipidemia in reducing triglycerides

and raising HDL-C compared with statin monotherapy.

\section{NOVEL HDL-C DIRECTED THERAPEUTIC STRATEGIES}

There are four different therapeutic approaches to improve HDL-C (see Table 2):

1. Directly augmenting the concentration of apolipoprotein A-I (apo A-I), the major protein constituent of HDL

2. Indirectly augmenting the concentration of apo A-I and HDL-C

3. Mimicking the functionality of apo A-I

4. Enhancing reverse cholesterol transport.

\section{Directly Augmenting Apo A-I Levels}

Recombinant HDL: Lipid-poor apo A-I, also termed nascent HDL or pre $\beta-H D L$, initiates reverse cholesterol transport by activating macrophage (ABCA1) and accepting effluxed cholesterol. From a pharmacodynamic standpoint, direct augmentation of lipid-poor apo A-I concentration arguably represents the most validated HDL-related therapeutic approach in terms of anti-atherogenic potential.

Lipid-poor apo A-I-phospholipid complexes, sometimes referred to as recombinant $\mathrm{HDL}$ ( $\mathrm{rHDL}$ ), have been studied extensively in animals and 
in preliminary studies in humans. Preclinical studies have demonstrated that the administration of apo A-I is associated with the inhibition or regression of atherosclerosis (51-54), enhanced macrophage-specific reverse cholesterol transport (55) and the inhibition of vascular inflammatory pathways (56). Moreover, short exploratory clinical studies of rHDL infusion have yielded decreases in coronary atherosclerosis, as assessed by coronary imaging, comparable with those obtained with long-term statin use at doses associated with improved clinical outcomes. These findings support the therapeutic potential of intravenous apo A-I infusion $(57,58)$.

ApoA-1 Milano: The apo A-I Milano mutation was first identified in a cohort of Italian patients who exhibited a decreased prevalence of atherosclerosis despite very low levels of HDL-C (10-20 mg/dl) (53). The effects of apo A-I Milano complexed with phospholipid (1-palmitoyl-2-oleoyl-sn-glycero-3-phosphocholine), also known as ETC-216, have been studied in animals and humans (58). In support of an anti-atherogenic activity, infusions of ETC-216 in rabbit and mouse models of atherosclerosis were associated with considerable reductions in the lipid and macrophage content of plaque (60-62).

In a small clinical study of 47 patients with acute coronary syndrome, five weekly doses of $15-45 \mathrm{mg} / \mathrm{kg}$ of ETC-216 significantly reduced 
total atheroma volume by $14.1 \mathrm{~mm} 3$ compared with baseline (4.2\%; $P$ $<0.001$ ), as measured by coronary intravascular ultrasonography (IVUS) (58) . Total atheroma volume did not change significantly with the administration of placebo $(-0.2 \mathrm{~mm} 3 ; P=0.97)$.

Wild type Apo A-I: Human plasma derived wild-type apoA-1 linked to soybean phospholipid (CSL111) was infused at $40 \mathrm{mg} / \mathrm{kg}$ per infusion in humans in a small proof of concept trial (63). Five weekly infusions did not show a significant benefit on coronary plaque progression in comparison with placebo. However, when compared with pretreatment baseline, apoA-1 recipients showed regression in contradistinction to the placebo arm (63). The $80 \mathrm{mg} / \mathrm{kg}$ per infusion regimen was abandoned because of hepatic toxicity even though a single infusion of $80 \mathrm{mg} / \mathrm{kg}$, in an unrelated study, was shown to favorably change femoral artery plaque composition (64). Overall, short-term infusion of synthetic HDL (containing apo A-I Milano or wild-type apoA-1) holds considerable promise as a potential strategy for rapid plaque remodeling and stabilization that could later be sustained with the use of orally LDL-C lowering and HDL-C raising agents, or even possibly repeated infusions. However, this requires further study.

Autologous Delipidated HDL: Another novel technique for increasing HDL-C involves the collection of $1 \mathrm{~L}$ of plasma by apheresis. 
The technique includes over 2 hours of apheresis followed by selective lipid removed from HDL using organic solvents to produce lipid-poor pre-b HDL. The lipid-poor pre-b HDL, which is a more efficient acceptor of cholesterol, is then reinfused back into the patient. In a small human trial involving 28 patients with acute coronary syndrome, 7 weekly treatments resulted in a $5.2 \%$ decrease in atheroma volume compared with baseline (65). Small clinical trials using intravascular ultrasound of the coronary arteries showed a similar $3.5 \%$ to $5 \%$ decrease in atheroma volume compared with baseline, but due to the small sample sizes were not statistically significantly different from placebo.

\section{Indirectly Augmenting Apo A-1 Levels}

Oral Upregulator of Endogenous Apo A-1: RVX-208, an oral upregulator of endogenous Apo A-1 selectively induces nuclear transporter factors which in turn induces hepatic and intestinal production of Apo Al. This compound significantly increases HDL-C by more than $40 \%$ in monkeys, and the serum of treated animals was shown to enhance cholesterol efflux from foam cells (66). Significant increases in total plasma Apo Al were demonstrated in a small short-term human trial, but most of the increase was in pre-b HDL. RVX-208 was the first oral small molecule that stimulates Apo Al production to enter phase 2 trials. 


\section{Niacin Receptor Agonists}

Niacin, the first antidyslipidemic agent identified, remains the most potent drug in use for increasing levels of HDL-C and apo A-I. However, the side effect of flushing of the face and upper body reduces compliance and leads to discontinuation of therapy in up to $25 \%$ to $40 \%$ of patients (44). The discovery of the niacin receptor GPR109A90 promised to usher in a new era in which the molecular mechanisms underlying the effects of niacin on lipids, and its adverse effects could be clearly defined (67). Co administration of the DP1 antagonist laropiprant reduces the incidence of the skin-related adverse effects of niacin (68). However, flushing still occurs in over half of the patients, and discontinuation of niacin treatment owing to severe skin-related symptoms remains a problem (69). A study in mice implicated keratinocyte-produced prostaglandin, PGE2 as a key mediator of niacin-induced skin flushing, suggesting that this molecule might be another potential target to minimize flushing $(70,71)$.

\section{Mimicking Apo A-I Functionality}

Another HDL-directed therapeutic approach utilizes small peptides that mimic one or more of the functions of apo A-I $(72,73)$. The most well-studied apo A-I mimetic, 4F, consists of 18 amino acids designed to share the lipid-binding properties of apo A-I through a common secondary structure, the class A amphipathic helix (74). The only 
reported human study of D-4F to date hints at the possibility of a benefit for this compound in humans (75). Compared with HDL isolated from individuals who received placebo, HDL isolated from individuals treated with a single $300 \mathrm{mg}$ or $500 \mathrm{mg}$ dose of unformulated D-4F increased the inhibition of LDL-induced monocyte chemotaxis in cultures of human aortic endothelial cells. As in animal studies, neither changes in apo A-I or HDL-C levels nor serious toxicity were observed in treated individuals.

\section{Enhancing reverse cholesterol transport}

\section{CETP Inhibitors}

CETP plays an important role in cholesterol metabolism, as it is responsible for the transfer of cholesteryl esters from HDL-C to VLDL-C and LDL-C (see Figure 1). CETP is a very large protein and has a hydrophobic tunnel across the molecule that can accommodate neutral lipid. CETP is a shuttle-type structure that promotes an equal mass gradient transfer of triglyceride for cholesterol ester between HDL and Apo-B lipoprotein (76). CETP plays an important role in maintaining a uniform distribution throughout the bloodstream and moves triglycerides where they are high (i.e., VLDL-C) to where they are low (HDL-C and LDL-C) in exchange for an equal mass gradient of cholesterol ester. Animals that lack CETP have very high HDL-C and very low LDL-C. CETP is important in modulating HDL size by 
redistributing cholesterol ester from triglyceride-rich particles into HDL particle. The triglyceride-enriched HDL is further acted on by hepatic lipase to form a smaller dense HDL that is more rapidly catabolized.

CETP is also involved in transporting triglycerides in exchange for cholesterol ester from triglyceride-rich particles to LDL. LDL becomes triglyceride enriched and further hydrolyzed by the lipases to form a small dense atherogenic LDL. Theoretically inhibition of CETP should therefore result in beneficial effects on HDL-C and LDL-C which could translate into decreased atherogenesis and reduced cardiovascular events.

In the Investigation of Lipid Level Management to Understand its Impact in Atherosclerotic Events (ILLUMINATE) which involved patients receiving atorvastatin were randomized to torcetrapib or placebo (77). Torcetrapib worsened the primary combined cardiovascular end point of death from coronary heart disease, nonfatal myocardial infarction, stroke, and hospitalization for unstable angina (hazard ratio [HR] 1.25, $95 \% \mathrm{Cl} 1.09-1.44, P=0.001$ ) as well as all-cause mortality (HR 1.58, $95 \% \mathrm{Cl} 1.14-2.19, P=0.006)$ compared with placebo after 12 months. This was despite torcetrapib increasing HDL-C by $72 \%$ and decreasing LDL-C by $25 \%$. The worrisome results of ILLUMINATE were paralleled by negative imaging findings in trials in which coronary and carotid 
ultrasonography were used $(78,79)$. These negative findings have been at least partly attributed to the off-target effects of torcetrapib, such as the raising of systolic blood pressure by an average of 5.4 $\mathrm{mmHg}$. As suggested by aldosterone measurements from participants in ILLUMINATE (77), findings from animal models (80) and human adrenal cell assays (81) suggest these off-target effects may be related to stimulation of aldosterone synthesis by torcetrapib via pathways independent of CETP inhibition.

Could inhibition of CETP activity explain some of the adverse effects observed in the clinical development program of torcetrapib? Initial concerns about CETP inhibition highlighted the possibility that the formation of large cholesterol-rich HDL particles resulting from CETP inhibition might be associated with impaired cholesterol efflux from peripheral macrophages to these particles (82). However, studies of patients either deficient in CETP or treated with a CETP inhibitor demonstrated not reduced, but rather enhanced, efflux of cholesterol via $A B C G 1$ to $H D L-C(83,84)$. Thus, an important step of reverse cholesterol transport remains intact, if not improved, in the setting of CETP inhibition.

On the other hand, the net effect of CETP inhibition on reverse cholesterol transport might depend, in part, on the effects of CETP on 
the hepatic uptake of HDL-derived cholesterol. The hepatic uptake of HDL-C can be direct, or occur after transfer of HDL-C via CETP to apo B-containing lipoproteins, which are then taken into the liver via the LDL receptor. As illustrated by macrophage-specific reverse cholesterol transport assays, in the setting of highly effective LDL clearance, CETP can actually enhance reverse cholesterol transport and have an atheroprotective role. However, when LDL clearance is impaired, CETP can slow down reverse cholesterol transport and thus be proatherogenic (85). The interdependence of terminal reverse cholesterol transport pathways suggests that individuals who are most likely to benefit from CETP inhibition are those with suboptimal LDL-receptor-mediated hepatic uptake of cholesterol.

Fortunately, at least two novel compounds apparently lacking the off-target effects of torcetrapib enable further testing of the CETP-inhibition strategy, namely dalcetrapib and anacetrapib.

Dalcetrapib: Dalcetrapib binds CETP irreversibly and is considerably less-potent than torcetrapib (86). A study in a hamster model suggested that dalcetrapib promotes reverse cholesterol transport (87). In a human study, among individuals with mean baseline HDL-C and LDL-C levels of $47 \mathrm{mg} / \mathrm{dl}$ and $144 \mathrm{mg} / \mathrm{dl}$, respectively, monotherapy with $600 \mathrm{mg}$ of dalcetrapib daily increased HDL-cholesterol 
levels by $23 \%$ compared with placebo administration, after 4 weeks of treatment (88). Among patients with type II dyslipidemia receiving 40 mg of pravastatin daily and whose baseline levels of HDL-C and LDL-C were $48 \mathrm{mg} / \mathrm{dl}$ and $120 \mathrm{mg} / \mathrm{dl}$, respectively, the addition of $600 \mathrm{mg}$ of dalcetrapib daily increased HDL-cholesterol levels by $28 \%$ and decreased LDL-cholesterol levels by $7 \%$ compared with placebo administration, after 4 weeks of treatment (89). After 24 weeks of therapy with $900 \mathrm{mg}$ of dalcetrapib daily, HDL-C levels increased by $33 \%$ (mean baseline level of $42 \mathrm{mg} / \mathrm{dl}$ ) in patients at high risk of coronary heart disease events who were treated with $10-80 \mathrm{mg}$ of atorvastatin daily, when compared with HDL levels in participants receiving placebo plus atorvastatin (90). LDL-C levels, however, did not differ in the two patient groups (mean baseline level of $74 \mathrm{mg} / \mathrm{dl}$ ). Importantly, no changes in blood pressure or aldosterone levels were observed with the use of high-dose dalcetrapib $(900 \mathrm{mg}$ ).

Dal-PLAQUE (91) was a phase Ilb, double-blind trial conducted at 11 centers in patients with CHD or CHD risk equivalents, treated with LDL-C lowering drugs to LDL-C $<100 \mathrm{mg} / \mathrm{dL}$ ( $<2.6 \mathrm{mmol} / \mathrm{L}$ ). Patients were randomized to dalcetrapib $600 \mathrm{mg}$ or placebo daily for 24 months, with a 2-week safety follow-up. Endpoints included indices of plaque burden from the right and left carotid and abdominal aorta determined by magnetic resonance imaging (MRI) after 24 months, 
and plaque inflammation using 18F-fluoro-deoxyglucose uptake measured by positron emission tomography/computed tomography (PET/CT) after 6 months. 189 subjects were screened and 130 randomized into the trial. Based on MRI, a significant reduction in total vessel area and a trend towards reduction in average wall area were observed with dalcetrapib vs. placebo after 24 months $\left(-4.01 \mathrm{~mm}^{2}\right.$ $[-7.23,-0.80] ; p=0.041$ and $-2.20 \mathrm{~mm}^{2}[-4.54,0.13] ; p=0.120$ respectively). Other indices of plaque burden were numerically reduced from baseline with dalcetrapib versus placebo. Based on PET/CT, mean of maximum standardized uptake value and target to background ratio were unchanged with dalcetrapib versus placebo after 6 months. HDL-C increased by 31\% with dalcetrapib after 24 months with no significant increases in inflammatory biomarkers. Dalcetrapib was well tolerated with a safety profile similar to placebo and was not associated with an increase in blood pressure.

Dal-PLAQUE 2 (92) will also assess changes in atherosclerotic plaque (morphology, composition, and inflammatory activity) among patients with CHD treated with $600 \mathrm{mg}$ of dalcetrapib daily.

Dal-VESSEL (93) was an exploratory phase Ilb randomized, double-blind, placebo-controlled trial in patients with $\mathrm{CHD}$ or CHD risk equivalents, in which 476 patients with HDL-C levels $<50 \mathrm{mg} / \mathrm{dL}$ were 
recruited. They received dalcetrapib $600 \mathrm{mg} /$ day or placebo in addition to their existing treatments. The primary efficacy endpoint was change from baseline in brachial flow mediated dilation after 12 weeks. The primary safety endpoint was 24-hour ambulatory blood pressure monitoring assessed at week four. Patients were treated for a total period of 36 weeks. Results showed that dalcetrapib reduced CETP activity by almost $50 \%$ and increased HDL-C levels by $31 \%$ without changing nitric-oxide-dependent endothelial function or markers of inflammation and oxidative stress. Dalcetrapib did not increase 24-hour ambulatory blood pressure (ABPM) at week 4, the primary safety endpoint.

Finally, the phase III clinical trial Dal-Outcomes (94) will evaluate the effects of adding $600 \mathrm{mg}$ of dalcetrapib daily to optimum pharmacotherapy in patients with acute coronary syndrome over a 2 year follow up period, with results expected in 2013.

Anacetrapib: Anacetrapib inhibits CETP by forming a tight reversible bond (95). Healthy individuals with mean baseline HDL-C and LDL-C of $51 \mathrm{mg} / \mathrm{dl}$ and $138 \mathrm{mg} / \mathrm{dl}$, respectively after receiving $300 \mathrm{mg}$ of anacetrapib daily for 10 days showed increases in HDL-C by $129 \%$ and decreases in LDL-C by 38\% (96). No changes in blood pressure, assessed through $24 \mathrm{~h}$ ambulatory monitoring, were observed. Among 
patients with dyslipidemia who had mean baseline HDL-C and LDL-C of $50 \mathrm{mg} / \mathrm{dl}$ and $141 \mathrm{mg} / \mathrm{dl}$, respectively, addition of $300 \mathrm{mg}$ of anacetrapib to $20 \mathrm{mg}$ of atorvastatin daily for 8 weeks increased HDL-C by $120 \%$ and decreased LDL-C by $30 \%$ compared with statin monotherapy (97). Interestingly, lipoprotein (a) levels, which were unchanged by statin therapy, decreased by $50 \%$ following anacetrapib administration.

The phase III Determining the Efficacy and Tolerability of CETP Inhibition with Anacetrapib (DEFINE) randomized, placebo-controlled trial examined the effect of $100 \mathrm{mg}$ of anacetrapib administered daily for 18 months to 1623 CHD or CHD equivalent patients who had achieved LDL-C treatment goals with statin therapy(98). The primary end points were the percent change in LDL-C at 24 weeks and the safety profile of anacetrapib at 76 weeks. HDL-C and other lipid parameters including lipoprotein (a) were assessed as secondary endpoints (94). Treatment with anacetrapib was associated with a $40 \%$ reduction in LDL-C from $81 \mathrm{mg} / \mathrm{dl}$ to $45 \mathrm{mg} / \mathrm{dl}(\mathrm{P}<0.001)$ and a 138\% increase in HDL-C from $41 \mathrm{mg} / \mathrm{dl}$ to $101 \mathrm{mg} / \mathrm{dl}(P<0.001)$ compared with placebo. Lipoprotein (a) decreased 36\% compared with placebo from $27 \mathrm{nmol} / \mathrm{l}$ to $15 \mathrm{nmol} / \mathrm{l}$. No increases in clinic-based blood pressure, serum aldosterone levels, or cardiovascular events were observed following anacetrapib treatment at 76 weeks. Supported by 
these substantial improvements in LDL-C, HDL-C, and lipoprotein (a), as well as an apparently benign safety profile, the Randomized EValuation of the Effects of Anacetrapib Through Lipid-modification (REVEAL) is scheduled to begin in April 2011(100). This study will examine major coronary events in 30,000 patients with coronary heart disease, cerebrovascular atherosclerotic disease, or peripheral artery disease (see Table 3).

\section{Agonists of the Liver X Receptor}

Liver $\mathrm{X}$ receptors (LXRs), which are members of the nuclear receptor superfamily, have a central role in lipid metabolism. Endogeneously activated by oxysterols, LXRs regulate the transcription of a myriad of target genes by binding to their promoters together with the retinoic acid receptor (101). With regard to HDL and reverse cholesterol transport, LXR activation has been demonstrated to promote mobilization of intracellular cholesterol (102), increase macrophage cholesterol efflux via macrophage ABCA1 and ABCG1 (103), and augment intestinal HDL generation (104). Therapeutic development of LXR agonists has been hindered by hepatic steatosis and increased plasma triglyceride concentrations reported in preclinical studies of these drugs (105).

\section{Endothelial lipase inhibitors}


Synthesized by and bound to vascular endothelial cells, endothelial lipase exhibits predominant phospholipase activity and affinity for HDL, unique characteristics among the lipoprotein-lipase family (106). An association between the expression of endothelial lipase and HDL-cholesterol levels was identified in overexpression and loss-of-function mouse models (107-109).Genetic studies indicate a similar association in humans, with rare and low-frequency loss-of-function variants of endothelial lipase, identified through deep sequencing, resulting in elevated HDL-cholesterol levels (110). How changes in HDL-cholesterol levels attributed to endothelial lipase ultimately affect atherosclerosis remains uncertain. Some human studies point to an atherogenic role of endothelial lipase, with a positive association between plasma levels of this enzyme and coronary artery calcification, features of the metabolic syndrome (such as impaired fasting glucose, and waist circumference), and inflammation $(111,112)$. Carriers of endothelial-lipase variants associated with raised HDL-cholesterol levels have been reported to have a decreased risk of atherothrombotic disease,(113) although this link has not been observed in other studies $(114,115)$. Of note, animal studies have shown that HDL-cholesterol levels do not always correlate with physiological changes associated with decreased atherosclerotic burden, with an endothelial-lipase knockout mouse model failing to demonstrate improved macrophage reverse cholesterol transport with 
raised HDL-cholesterol levels (116). More worrisome, in the setting of hepatic-lipase deficiency, is that the absence of endothelial lipase resulted in an accumulation of small dense LDL,(116) a particularly atherogenic subpopulation of LDL. These findings suggest that endothelial-lipase inhibition could potentially exert a detrimental effect on atherosclerosis, even though HDL-cholesterol levels are raised. Despite this uncertainty, endothelial lipase has been the object of substantial interest as a therapeutic target. High-throughput screening identified several compounds sharing a sulfonyl furan urea core as potent and selective endothelial-lipase inhibitors (117). Further evaluation of these and other small-molecule inhibitors of endothelial lipase has not been performed yet.

\section{Conclusions}

Targeting HDL-C is an integral component of the management of CHD and risk reduction. Several strategies can be used to increase HDL-C levels to target cardiovascular risk reduction, including pharmacologic management focused on the use of statin, statin combination therapy, and investigational drugs targeting HDL-C metabolism and reverse cholesterol transport. However, the negative results obtained from the ILLUMINATE and AIM-HIGH clinical trials suggest that improving HDL-C levels in plasma alone does not necessarily translate into cardiovascular risk reduction. Due to the complexity of HDL cholesterol 
metabolism and the wide variety of targets for improving HDL cholesterol levels, it is clear that further research is needed to determine which will be the safest, most cost-effective, and most efficacious for reducing both rates of atherogenesis and risk for acute cardiovascular events. Ongoing and future clinical trials will comprehensively evaluate these HDL cholesterol-raising therapies in patients in both the primary and secondary prevention settings. 


\section{REFERENCES}

1. American Heart Association. Heart disease and stroke statistics2012 update.

Dallas (TX): American Heart Association; 2012.

2. Smith SC, Allen J, Blair SN, et al. AHA/ACC guidelines for secondary prevention

for patients with coronary artery disease other atherosclerotic vascular

disease:2006 update: endorsed by the National Heart, Lung, and Blood Institute.

Circulation 2006;113:2363e72.

3. Duffy D, Rader DJ. Update on strategies to increase HDL quantity and function.

Nat Rev Cardiol 2009;6: 455e63.

4. Davidson MH, Toth PP. High-density lipoprotein metabolism: potential therapeutic

targets. Am J Cardiol 2007;100(11A):n32e40. 
5. Davidson $\mathrm{MH}$. Focus on HDL as a therapeutic target for CAD risk reduction. Am J

Cardiol 2009;104(Suppl 10):1Ee2E.

6. Hulley S, Ashman P, Kuller L, Lasser N, Sherwin R. HDL-cholesterol levels in the

Multiple Risk Factor Intervention Trial (MRFIT) by the MRFIT Research Group 1,2.

Lipids. 1979;14:119-123.

7. Keys A. Alpha lipoprotein (HDL) cholesterol in the serum and the risk of coronary heart disease and death. Lancet. 1980;2:603-606.

8. Ghali WA, Rodondi N. HDL cholesterol and cardiovascular risk. BMJ. 2009;338:a3065.

9. Fazio S, Linton MF. Elevated high-density lipoprotein (HDL) levels due to hepatic lipase mutations do not reduce cardiovascular disease risk: 
another strike against the HDL dogma. J Clin Endocrinol Metab. 2009;94:1081-1083.

10. Fazio S, Linton MF. Sorting out the complexities of reverse cholesterol transport: CETP polymorphisms, HDL, and coronary disease. J Clin Endocrinol Metab. 2006;91:3273-3275.

11. Fazio S, Linton MF. Apolipoprotein Al as therapy for atherosclerosis: does the future of preventive cardiology include weekly injections of the HDL protein? Mol Interv. 2003;3:436-440.

12. Franceschini G, Sirtori CR, Capurso A 2nd, Weisgraber KH, Mahley RW. A-IMilano apoprotein. Decreased high density lipoprotein cholesterol levels with significant lipoprotein modifications and without clinical atherosclerosis in an Italian family. J Clin Invest.1980;66:892-900.

13. Agerholm-Larsen B, Nordestgaard BG, Steffensen R, Jensen G, Tybjaerg-Hansen A. Elevated HDL cholesterol is a risk factor for ischemic heart disease in white women when caused by a common mutation in the cholesteryl ester transfer protein gene. Circulation.2000;101:1907-1912. 
14. Borggreve SE, Hillege HL, Dallinga-Thie GM, et al. High plasma cholesteryl ester transfer protein levels may favour reduced incidence of cardiovascular events in men with low triglycerides. Eur Heart J. 2007;28:1012-1018.

15. Saito Y. Is cholesteryl ester transfer protein (CETP) deficiency atherogenic in familial hypercholesterolemia. Intern Med. 1998;37: 495-496.

16. Zhong S, Sharp DS, Grove JS, Bruce C, Yano K, Curb JD, Tall AR. Increased coronary heart disease in Japanese-American men with mutation in the cholesteryl ester transfer protein gene despite increased HDL levels. J Clin Invest. 1996;97:2917-2923.

17. Borggreve SE, Hillege HL, Wolffenbuttel BH, et al. An increased coronary risk is paradoxically associated with common cholesteryl estertransfer protein gene variations that relate to higher high-density lipoprotein cholesterol: a population-based study. J Clin Endocrinol Metab. 2006;91:3382-3388.

18. Johannsen TH, Kamstrup PR, Andersen RV, et al. Hepatic lipase, genetically elevated high-density lipoprotein, and risk of ischemic cardiovascular disease. J Clin Endocrinol Metab. 2009;94:1264-1273. 
19. deGoma EM, deGoma RL, Rader DJ. Beyond high-density lipoprotein cholesterol levels evaluating high-density lipoprotein function as influenced by novel therapeutic approaches. J Am Coll Cardiol. 2008;51: 2199-2211.

20. Rye KA, Bursill CA, Lambert G, Tabet F, Barter PJ. The metabolism and anti-atherogenic properties of HDL. J Lipid Res. 2009;50(Suppl): S195-S200.

21. Sviridov D, Mukhamedova N, Remaley AT, Chin-Dusting J, Nestel P. Antiatherogenic functionality of high density lipoprotein: how much versus how good. J Atheroscler Thromb. 2008;15:52-62.

22. Ansell BJ, Navab M, Hama S, et al. Inflammatory/anti-inflammatory properties of high-density lipoprotein distinguish patients from control subjects better than high-density lipoprotein cholesterol levels and are favorably affected by simvastatin treatment. Circulation. 2003;108: 2751-2756.

23. van der Steeg WA, Holme I, Boekholdt SM, et al. High-density lipoprotein cholesterol, high-density lipoprotein particle size, and 
apolipoprotein A-I: significance for cardiovascular risk: the IDEAL and EPIC-Norfolk studies. J Am Coll Cardiol. 2008;51:634-642.

24. Assmann G, von Eckardstein A, Funke H. High density lipoproteins, reverse transport of cholesterol, and coronary artery disease. Insights from mutations. Circulation. 1993;87:III28-III34.

25. Petraki MP, Mantani PT, Tselepis AD. Recent advances on the antiatherogenic effects of HDL-derived proteins and mimetic peptides. Curr Pharm Des. $2009 ; 15: 3146-3166$.

26. Ansell BJ, Fonarow GC, Fogelman AM. The paradox of dysfunctional high-density lipoprotein. Curr Opin Lipidol. 2007;18:427-434.

27. Acton S, Rigotti A, Landschulz KT, Xu S, Hobbs HH, Krieger M. Identification of scavenger receptor SR-BI as a high density lipoprotein receptor. Science. 1996;271:518-520.

28. McPherson R, Marcel Y. Role of cholesteryl ester transfer protein in reverse cholesterol transport. Clin Cardiol. 1991;14:I31-I34. 
29. Graversen JH, Castro G, Kandoussi A, et al. A pivotal role of the human kidney in catabolism of HDL protein components apolipoprotein A-I and A-IV but not of A-II. Lipids. 2008;43:467-470.

30. Hammad SM, Barth JL, Knaak C, Argraves WS. Megalin acts in concert with cubilin to mediate endocytosis of high density lipoproteins. J Biol Chem. 2000;275:12003-12008.

31. Zannis VI, Chroni A, Krieger M. Role of apoA-I, ABCA1, LCAT, and SR-BI in the biogenesis of HDL. J Mol Med. 2006;84:276-294.

32. Lorenzi I, von Eckardstein A, Radosavljevic S, Rohrer L. Lipidation of apolipoprotein A-I by ATP-binding cassette transporter (ABC) A1 generates an interaction partner for ABCG1 but not for scavenger receptor Bl. Biochim Biophys Acta. 2008;1781:306-313.

33. Vaughan $A M$, Oram JF. $A B C A 1$ and $A B C G 1$ or $A B C G 4$ act sequentially to remove cellular cholesterol and generate cholesterol-rich HDL. J Lipid Res. 2006;47:2433-2443.

34. Yancey PG, Jerome WG, Yu H, et al. Severely altered cholesterol homeostasis in macrophages lacking apoE and SR-BI. J Lipid Res. 2007;48:1140-1149. 
35. Vaisar T, Pennathur S, Green PS, et al. Shotgun proteomics implicates protease inhibition and complement activation in the anti-inflammatory properties of HDL. J Clin Invest. 2007;117:746-756.

36. Navab M, Ananthramaiah GM, Reddy ST, et al. The oxidation hypothesis of atherogenesis: the role of oxidized phospholipids and HDL. J Lipid Res. 2004;45:993-1007.

37. National Cholesterol Education Panel. Third Report of the National Cholesterol Education Program (NCEP) Expert Panel on Detection, Evaluation, and Treatment of High Blood Cholesterol in Adults (Adult Treatment Panel III) final report. Circulation 2002;106:3143e421.

38. Davidson $\mathrm{MH}$, Rosenson RS. Novel targets that affect high-density lipoprotein metabolism: the next frontier. Am J Cardiol 2009;104(10 Suppl):52Ee7E.

39. Study of Coronary Atheroma by Intravascular Ultrasound: effect of Rosuvastatin Versus Atorvastatin (SATURN). Available at: http://clinicaltrials.gov/ct2/ show/NCT00620542. Accessed October 30, 2010. 
40. Berge KG, Canner PL. Coronary drug project: experience with niacin. Coronary Drug Project Research Group. Eur J Clin Pharmacol 1991;40(Suppl 1): S49e51.

41. Kamanna VS, Kashyap ML. Mechanism of action of niacin on lipoprotein metabolism. Curr Atheroscler Rep 2000;2:36e46.

42. Pike NB. Flushing out the role of GPR109A (HM74A) in the clinical efficacy of nicotinic acid. J Clin Invest 2005;115(12):3400e3.

43. Cheng K, Wu TJ, Wu KK, et al. Antagonism of the prostaglandin D2 receptor 1 suppresses nicotinic acid-induced vasodilation in mice and humans. Proc Natl Acad Sci U S A 2006;103:6682e7.

44. Guyton JR, Bays HE. Safety considerations with niacin therapy. Am J Cardiol 2007; 99:22C-31C.

45. Taylor AJ, Sullenberger LE, Lee HJ, et al. Arterial biology for the investigation of the treatment effects of reducing cholesterol (ARBITER) 2. Circulation 2004;110:3512e7.

46 ClinicalTrials.gov. Niacin plus statin to prevent vascular events [online], http://clinicaltrials.gov/ct2/show/NCT00120289 (2010). 
47. ClinicalTrials.gov. Treatment of HDL to reduce the incidence of vascular events HPS2-THRIVE [online], http://clinicaltrials.gov/ct2/show/NCT00461630 (2010).

48. Jones PH, Cusi K, Davidson MH, et al. Efficacy and safety of fenofibric acid co-administered with low- or moderate-dose statin in patients with mixed dyslipidemia and type 2 diabetes mellitus: results of a pooled subgroup analysis from three randomized, controlled, double-blind trials. Am J Cardiovasc Drugs 2010;10:73e84.

49. Davidson MH, Rooney MW, Drucker J, et al. Efficacy and tolerability of atorvastatin/fenofibrate fixed-dose combination tablet compared with atorvastatin and fenofibrate monotherapies in patients with dyslipidemia: a 12-week, multicenter, double-blind, randomized, parallel-group study. Clin Ther $2009 ; 12: 2824 \mathrm{e} 38$

50. Badimon, J. J., Badimon, L. \& Fuster, V. Regression of atherosclerotic lesions by high density lipoprotein plasma fraction in the cholesterol-fed rabbit. J. Clin. Invest. 85, 1234-1241 (1990). 
51. Chiesa, G. et al. Recombinant apolipoprotein A-I(Milano) infusion into rabbit carotid artery rapidly removes lipid from fatty streaks. Circ. Res. 90, 974-980 (2002).

52. Parolini, C. et al. Dose-related effects of repeated ETC-216 (recombinant apolipoprotein A-I Milano/1-palmitoyl-2-oleoyl phosphatidylcholine complexes) administrations on rabbit lipid-rich soft plaques: in vivo assessment by intravascular ultrasound and magnetic resonance imaging. J. Am. Coll. Cardiol. 51, 1098-1103 (2008).

53. Badimon, J. J., Badimon, L., Galvez, A., Dische, R. \& Fuster, V. High density lipoprotein plasma fractions inhibit aortic fatty streaks in cholesterol-fed rabbits. Lab. Invest. 60, 455-461 (1989).

54. Shah, P. K. et al. Effects of recombinant apolipoprotein A-I(Milano) on aortic atherosclerosis in apolipoprotein E-deficient mice. Circulation 97, 780-785 (1998).

55. Zhang, Y. et al. Overexpression of apolipoprotein A-I promotes reverse transport of cholesterol from macrophages to feces in vivo. Circulation 108, 661-663 (2003). 
56. Barter, P. J. et al. Antiinflammatory properties of HDL. Circ. Res. 95, 764-772 (2004).

57. Nicholls, S. J. et al. Reconstituted high-density lipoproteins inhibit the acute pro-oxidant and proinflammatory vascular changes induced by a periarterial collar in normocholesterolemic rabbits. Circulation 111, 1543-1550 (2005).

58. Nissen, S. E. et al. Effect of recombinant ApoA-I Milano on coronary atherosclerosis in patients with acute coronary syndromes: a randomized controlled trial. JAMA 290, 2292-2300 (2003).

59. Sirtori, C. R. et al. Cardiovascular status of carriers of the apolipoprotein A-I(Milano) mutant: the Limone sul Garda study. Circulation 103, 1949-1954 (2001).

60. Kaul S, Rukshin V, Santos R, et al. Intramural delivery of recombinant apolipoprotein A-IMilano/phospholipid complex (ETC-216) inhibits in-stent stenosis in porcine coronary arteries. Circulation 2003;107(20):2551-4. 
61. Ameli, S. et al. Recombinant apolipoprotein A-I Milano reduces intimal thickening after balloon injury in hypercholesterolemic rabbits. Circulation 90, 1935-1941 (1994).

62. Shah, P. K. et al. High-dose recombinant apolipoprotein A-I(milano) mobilizes tissue cholesterol and rapidly reduces plaque lipid and macrophage content in apolipoprotein e-deficient mice. Potential implications for acute plaque stabilization. Circulation 103, 3047-3050 (2001).

63. Tardif JC, Gregoire J, L'Allier PL, et al. Effects of reconstituted high-density lipoprotein infusions on coronary atherosclerosis: a randomized controlled trial. JAMA 2007;297(15):1675e82.

64. Shaw JA, Bobik A, Murphy A, et al. Infusion of reconstituted high-density lipoprotein leads to acute changes in human atherosclerotic plaque. Circ Res 08;103(10):1084e91

65. Waksman, R. et al. A first-in-man, randomized, placebo-controlled study to evaluate the safety and feasibility of autologous delipidated high-density lipoprotein plasma infusions in patients with acute coronary syndrome. J. Am. Coll. Cardiol. 55, 2727-2735 (2010). 
66. Bailey, D. et al. RVX-208: a small molecule that increases apolipoprotein A-I and high-density lipoprotein cholesterol in vitro and in vivo. J. Am. Coll. Cardiol. 55, 2580-2589 (2010).

67.Tunaru, S. et al. PUMA-G and HM74 are receptors for nicotinic acid and mediate its anti-lipolytic effect. Nat. Med. 9, 352-355 (2003).

68. Maccubbin, D. et al. Flushing profile of extended-release niacin/laropiprant versus gradually titrated niacin extended-release in patients with dyslipidemia with and without ischemic cardiovascular disease. Am. J. Cardiol. 104, 74-81 (2009).

69. Maccubbin, D. et al. Flushing profile of extended-release niacin/laropiprant versus gradually titrated niacin extended-release in patients with dyslipidemia with and without ischemic cardiovascular disease. Am. J. Cardiol. 104, 74-81 (2009).

70. Hanson, J. et al. Nicotinic acid- and monomethyl fumarate-induced flushing involves GPR109A expressed by keratinocytes and COX-2-dependent prostanoid formation in mice. J. Clin. Invest. 120, 2910-2919 (2010). 
71. Dunbar, R. L. \& Gelfand, J. M. Seeing red: flushing out instigators of niacin-associated skin toxicity. J. Clin. Invest. 120, 2651-2655 (2010).

72. Van Lenten, B. J. et al. Apolipoprotein A-I mimetic peptides. Curr. Atheroscler. Rep. 11, 52-57 (2009).

73. Navab, M. et al. The oxidation hypothesis of atherogenesis: the role of oxidized phospholipids and HDL. J. Lipid Res. 45, 993-1007 (2004).

74. Anantharamaiah, G. M. et al. Structural requirements for antioxidative and anti-inflammatory properties of apolipoprotein A-I mimetic peptides. J. Lipid Res. 48, 1915-1923 (2007).

75. Bloedon, L. T. et al. Safety, pharmacokinetics, and pharmacodynamics of oral apoA-I mimetic peptide D-4F in high-risk cardiovascular patients. J. Lipid Res. 49, 1344-1352 (2008).

76. Tall AR. The effects of cholesterol ester transfer protein inhibition on cholesterol efflux. Am J Cardiol 2009;104(Suppl):39Ee45E.

77. Barter, P. J. et al. Effects of torcetrapib in patients at high risk for coronary events. N. Engl. J. Med. 357, 2109-2122 (2007) 
78. Bots, M. L. et al. Torcetrapib and carotid intima-media thickness in mixed dyslipidaemia (RADIANCE 2 study): a randomised, double-blind trial. Lancet 370, 153-160 (2007).

79. Nicholls, S. J., Tuzcu, E. M., Brennan, D. M., Tardif, J. C. \& Nissen, S. E. Cholesteryl ester transfer protein inhibition, high-density lipoprotein raising, and progression of coronary atherosclerosis: insights from ILLUSTRATE.

80. Matsuura, F., Wang, N., Chen, W., Jiang, X. C. \& Tall, A. R. HDL from CETP-deficient subjects shows enhanced ability to promote cholesterol efflux from macrophages in an apoE- and ABCG1-dependent pathway. J. Clin. Invest. 116, 1435-1442 (2006).

81. Forrest, M. J. et al. Torcetrapib-induced blood pressure elevation is independent of CETP inhibition and is accompanied by increased circulating levels of aldosterone. Br. J. Pharmacol. 154, 1465-1473 (2008).

82. Ishigami, M. et al. Large and cholesteryl ester-rich high-density lipoproteins in cholesteryl ester transfer protein (CETP) deficiency can not protect macrophages from cholesterol accumulation induced by acetylated low-density lipoproteins. J. Biochem. 116, 257-262 (1994). 
83. Yvan-Charvet, L. et al. Inhibition of cholesteryl ester transfer protein by torcetrapib modestly increases macrophage cholesterol efflux to HDL. Arterioscler. Thromb. Vasc. Biol. 27, 1132-1138 (2007).

84. Yvan-Charvet, L. et al. Cholesterol efflux potential and antiinflammatory properties of high-density lipoprotein after treatment with niacin or anacetrapib. Arterioscler. Thromb. Vasc. Biol. 30, 1430-1438 (2010).

85. Tanigawa, H. et al. Expression of cholesteryl ester transfer protein in mice promotes macrophage reverse cholesterol transport. Circulation 116, 1267-1273 (2007).

86. Vergeer, M. \& Stroes, E. S. The pharmacology and off-target effects of some cholesterol ester transfer protein inhibitors. Am. J. Cardiol. 104 (10 Suppl.), 32E-38E (2009).

87. Niesor, E. J. et al. Modulating cholesteryl ester transfer protein activity maintains efficient pre- $\beta-H D L$ formation and increases reverse cholesterol transport. J. Lipid Res. 51, 3443-3454 (2010). 
88. de Grooth, G. J. et al. Efficacy and safety of a novel cholesteryl ester transfer protein inhibitor, JTT-705, in humans: a randomized phase II dose-response study. Circulation 105, 2159-2165 (2002).

89. Kuivenhoven, J. A. et al. Effectiveness of inhibition of cholesteryl ester transfer protein by JTT-705 in combination with pravastatin in type II dyslipidemia. Am. J. Cardiol. 95, 1085-1088 (2005).

90. Stein, E. A. et al. Safety and tolerability of dalcetrapib (R04607381/JTT-705): results from a 48-week trial. Eur. Heart J. 31, 480-488 (2010).

91. ClinicalTrials.gov. A study of the effect of dalcetrapib on artherosclerotic disease in patients with coronary artery disease [online], http://clinicaltrials.gov/ct2/show/NCT01059682 (2010).

92. ClinicalTrials.gov. A study of the effect of R04607381 on atherosclerotic plaque in patients with coronary heart disease [online], http://clinicaltrials.gov/ct2/show/NCT00655473 (2010).

93. ClinicalTrials.gov. A study assessing the effect of RO4607381 on vascular function in patients with coronary heart disease (CHD) 
orCHD-risk equivalent patients [online],

http://clinicaltrials.gov/ct2/show/NCT00655538 (2010).

94. ClinicalTrials.gov. A study of RO4607381 in stable coronary heart disease patients with recent acute coronary syndrome [online], http://clinicaltrials.gov/ct2/show/NCT00658515 (2010).

95. Ranalletta, M. et al. Biochemical characterization of cholesteryl ester transfer protein inhibitors. J. Lipid Res. 51, 2739-2752 (2010).

96. Krishna, R. et al. Effect of the cholesteryl ester transfer protein inhibitor, anacetrapib, on lipoproteins in patients with dyslipidaemia and on 24-h ambulatory blood pressure in healthy individuals: two double-blind, randomised placebo-controlled phase I studies. Lancet 370, 1907-1914 (2007).

97. Bloomfield, D. et al. Efficacy and safety of the cholesteryl ester transfer protein inhibitor anacetrapib as monotherapy and coadministered with atorvastatin in dyslipidemic patients. Am. Heart J. 157, 352-360 (2009). 
98. Cannon, C. P. et al. Design of the DEFINE trial: determining the EFficacy and tolerability of CETP INhibition with AnacEtrapib. Am. Heart J. $158,513-519$ (2009).

99. Cannon, C. P. et al. Safety of anacetrapib in patients with or at high risk for coronary heart disease. N. Engl. J. Med. 363, 2406-2415 (2010).

100. ClinicalTrials.gov. REVEAL: Randomized EValuation of the Effects of Anacetrapib through Lipid-modification [online], http://clinicaltrials.gov/ct2/show/NCT01252953 (2010).

101.Rader, D. J. Liver $\mathrm{X}$ receptor and farnesoid $\mathrm{X}$ receptor as therapeutic targets. Am. J. Cardiol. 100 (Suppl. 1), S15-S19 (2007).

102. Rigamonti, E. et al. Liver $\mathrm{X}$ receptor activation controls intracellular cholesterol trafficking and esterification in human macrophages. Circ. Res. 97, 682-689 (2005).

103. Costet, P., Luo, Y., Wang, N. \& Tall, A. R. Sterol-dependent transactivation of the $A B C 1$ promoter by the liver $X$ receptor/retinoid $X$ receptor. J. Biol. Chem. 275, 28240-28245 (2000).

104. Brunham, L. R. et al. Intestinal ABCA1 directly contributes to HDL 
biogenesis in vivo. J. Clin. Invest. 116, 1052-1062 (2006).

105. Grefhorst, A. et al. Stimulation of lipogenesis by pharmacological activation of the liver $\mathrm{X}$ receptor leads to production of large, triglyceride-rich very low density lipoprotein particles. J. Biol. Chem. $277,34182-34190(2002)$

106. Choi, S. Y., Hirata, K., Ishida, T., Quertermous, T. \& Cooper, A. D. Endothelial lipase: a new lipase on the block. J. Lipid Res. 43, 1763-1769 (2002).

107. Ishida, T. et al. Endothelial lipase is a major determinant of HDL level. J. Clin. Invest. 111, 347-355 (2003).

108. Jin, W., Millar, J. S., Broedl, U., Glick, J. M. \& Rader, D. J. Inhibition of endothelial lipase causes increased HDL cholesterol levels in vivo. J. Clin. Invest. 111, 357-362 (2003).

109. Jaye, M. et al. A novel endothelial-derived lipase that modulates HDL metabolism. Nat. Genet. 21, 424-428 (1999). 
110. Edmondson, A. C. et al. Loss-of-function variants in endothelial lipase are a cause of elevated HDL cholesterol in humans. J. Clin. Invest. 119, 1042-1050 (2009).

111. Badellino, K. O., Wolfe, M. L., Reilly, M. P. \& Rader, D. J. Endothelial lipase concentrations are increased in metabolic syndrome and associated with coronary atherosclerosis. PLoS Med. 3, e22 (2006).

112. Badellino, K. O., Wolfe, M. L., Reilly, M. P. \& Rader, D. J. Endothelial lipase is increased in vivo by inflammation in humans. Circulation 117, 678-685 (2008).

113. Tang, N. P. et al. Protective effect of an endothelial lipase gene variant on coronary artery disease in a Chinese population. J. Lipid Res. 49, 369-375 (2008).

114. Vergeer, M. et al. Lack of association between common genetic variation in endothelial lipase (LIPG) and the risk for CAD and DVT. Atherosclerosis 211, 558-564 (2010).

115. Jensen, M. K. et al. The T111l variant in the endothelial lipase gene and risk of coronary heart disease in three independent populations. Eur. Heart J. 30, 1584-1589 (2009). 
116. Brown, R. J. et al. Impact of combined deficiency of hepatic lipase and endothelial lipase on the metabolism of both high-density lipoproteins and apolipoprotein B-containing lipoproteins. Circ. Res. 107, 357-364 (2010).

117. Goodman, K. B. et al. Discovery of potent, selective sulfonylfuran urea endothelial lipase inhibitors. Bioorg. Med. Chem. Lett. 19, 27-30 (2009). 
Table 1: Traditional drug therapy used to increase HDL-C

\begin{tabular}{|c|c|c|c|c|}
\hline $\begin{array}{l}\text { Drug } \\
\text { Class }\end{array}$ & $\begin{array}{l}\text { HDL-C } \\
\text { Increase }\end{array}$ & Mechanism of Action & Side Effects & $\begin{array}{l}\text { Clinical Trial } \\
\text { Results }\end{array}$ \\
\hline Statins & $5 \%-15 \%$ & $\begin{array}{l}\text { 3-hydroxy-3-methyl- } \\
\text { glutaryl-CoA } \\
\text { reductase } \\
\text { (HMG-COA) inhibitor }\end{array}$ & $\begin{array}{l}\text { Myopathy, } \\
\text { Increased } \\
\text { liver } \\
\text { enzymes. }\end{array}$ & $\begin{array}{l}\text { Reduced major } \\
\text { coronary events, } \\
\text { CAD deaths, } \\
\text { need for } \\
\text { coronary } \\
\text { procedures, } \\
\text { stroke and total } \\
\text { mortality }\end{array}$ \\
\hline Niacin & $15 \%-35 \%$ & $\begin{array}{l}\text { Decreased } \\
\text { clearance of ApoA1 }\end{array}$ & $\begin{array}{l}\text { Flushing, } \\
\text { hepatotoxicit } \\
\text { y, } \\
\text { hyperuricemi } \\
\text { a, upper } \\
\text { gastrointestin } \\
\text { al distress, } \\
\text { hyperglycemi } \\
\text { a }\end{array}$ & $\begin{array}{l}\text { Reduced major } \\
\text { coronary events }\end{array}$ \\
\hline Fibrates & $10 \%-20 \%$ & $\begin{array}{l}\text { Peroxisome } \\
\text { proliferator- } \\
\text { activated } \\
\text { receptor-alpha } \\
(\text { PPAR- } \alpha \text { ) agonist }\end{array}$ & $\begin{array}{l}\text { Dyspepsia, } \\
\text { gallstones, } \\
\text { myopathy }\end{array}$ & $\begin{array}{l}\text { Reduced major } \\
\text { coronary events }\end{array}$ \\
\hline
\end{tabular}


Table 2:HDL- directed pharmacotherapeutic strategies

Directly augmenting apo A-1

Intravenous apo A-1 therapy

- Recombinant apoA-1 Milano/phospholipids (ETC-216)

- Purified native apoA-1/phospholipids (CSL-111/112)

- Autologous delipidated HDL

Indirectly augmenting apo A-1

- Oral upregulator of endogenous apoA-1 production (RVX-208)

- Niacin receptor (GPR109A) agonists

Mimicking Apo A1 Functionality

- Apo A-1 mimetic peptides

Enhancing reverse cholesterol transport

Cholesterol ester transfer protein inhibitors

- Dalcetrapib

- Anacetrapib

Liver $\mathrm{X}$ receptor agonists 
Table 3: Ongoing late-stage clinical trials of HDL-directed therapies

\begin{tabular}{|c|c|c|c|}
\hline Drug & Trial & Patient population (n) & $\begin{array}{l}\text { Anticipate } \\
\text { d } \\
\text { completio } \\
\text { n date }\end{array}$ \\
\hline \multicolumn{4}{|c|}{ CETP Inhibitors } \\
\hline Dalcetrapib & DAL-Outcomes & Acute coronary syndromes $(15,600)$ & 2013 \\
\hline Anacetrapib & REVEAL & $\begin{array}{l}\text { Stable coronary heart disease or risk } \\
\text { equivalent }(30,000)\end{array}$ & 2017 \\
\hline \multicolumn{4}{|l|}{ Niacin } \\
\hline $\begin{array}{l}\text { Niacin-laropipr } \\
\text { ant }\end{array}$ & HPS2-THRIVE & Stable vascular disease $(25,000)$ & 2013 \\
\hline
\end{tabular}




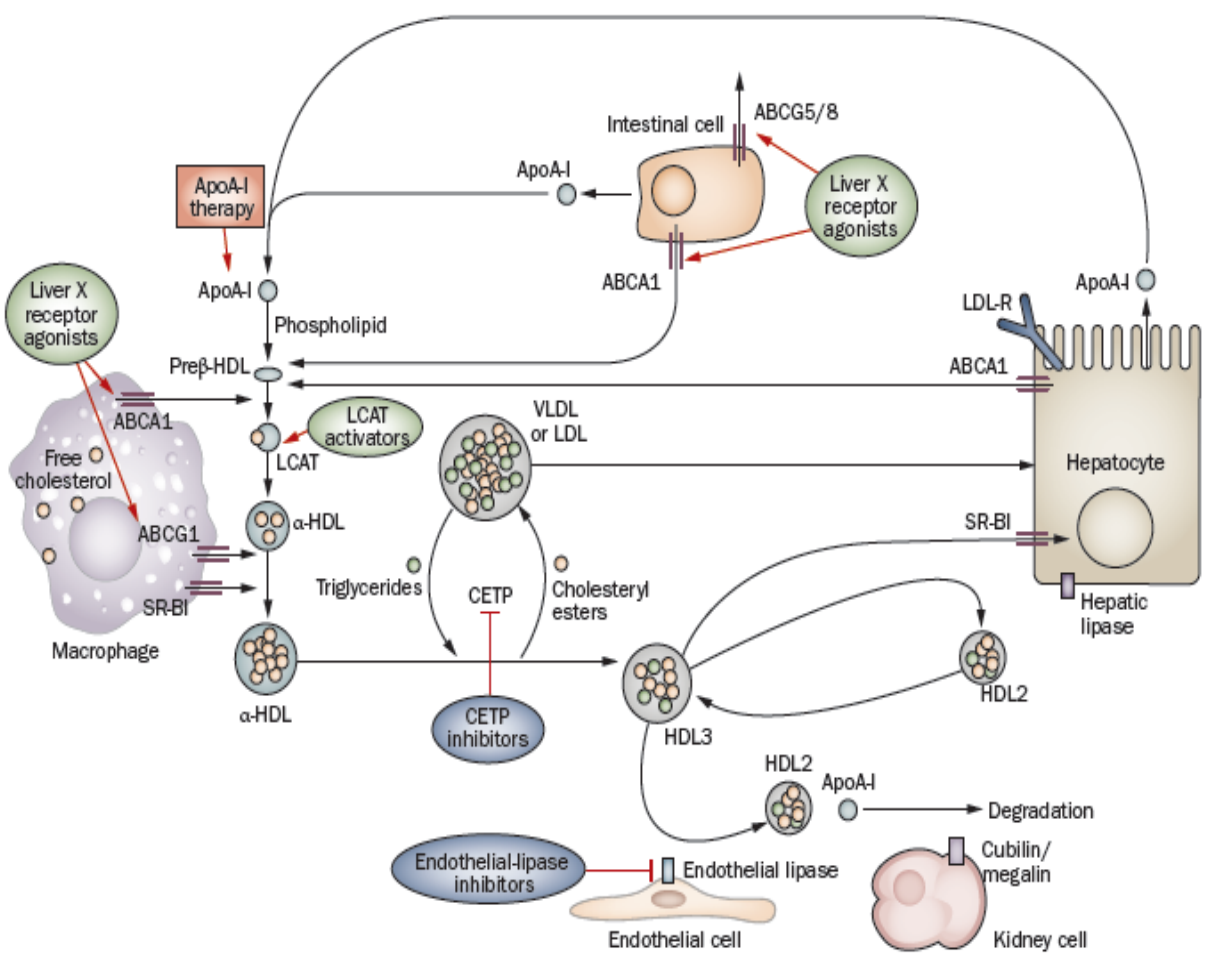

Flgure 1 | HDL metabolism and targets of therapeutic intervention. Synthesized by the liver and the intestine, apo A-I acquires phospholipid to form nascent preß-HDL. ABCA1 initiates the first step of reverse cholesterol transport, facilitating the efflux of free cholesterol from peripheral cells to nascent pre $\beta$-HDL. LCAT esterifies the cholesterol molecules to form cholesteryl esters, which migrate to the core of the HDL particle, resulting in formation of a-HDL. These mature HDL particles can acquire additional lipid via efflux mediated by ABCG1 and SR-BI. CETP mediates exchange of cholesteryl esters for triglycerides with VLDL or LDL, effecting depletion in cholesteryl esters and enrichment in triglycerides of HDL. The resulting HDL3 particles can be either taken up by the liver via SR-BI holoparticle uptake or modified by hepatic lipase and endothelial lipase. Metabolism by the latter releases lipid-poor apo A-I, which can be filtered by the glomeruli and degraded by cubilin/megalin in the proximal renal tubule. Targets of HDL-directed therapeutic interventions are indicated by red arrows and lines. Abbreviations: ABC, ATP-binding cassette transporter; Apo A-I, apolipoprotein A-I; CETP, cholesteryl ester transfer protein; CD36 and LIMPII analogous-1; LCAT, lecithin-cholesterol acyltransferase; LDL-R, LDL receptor; SR-BI, scavenger receptor class B type I. 


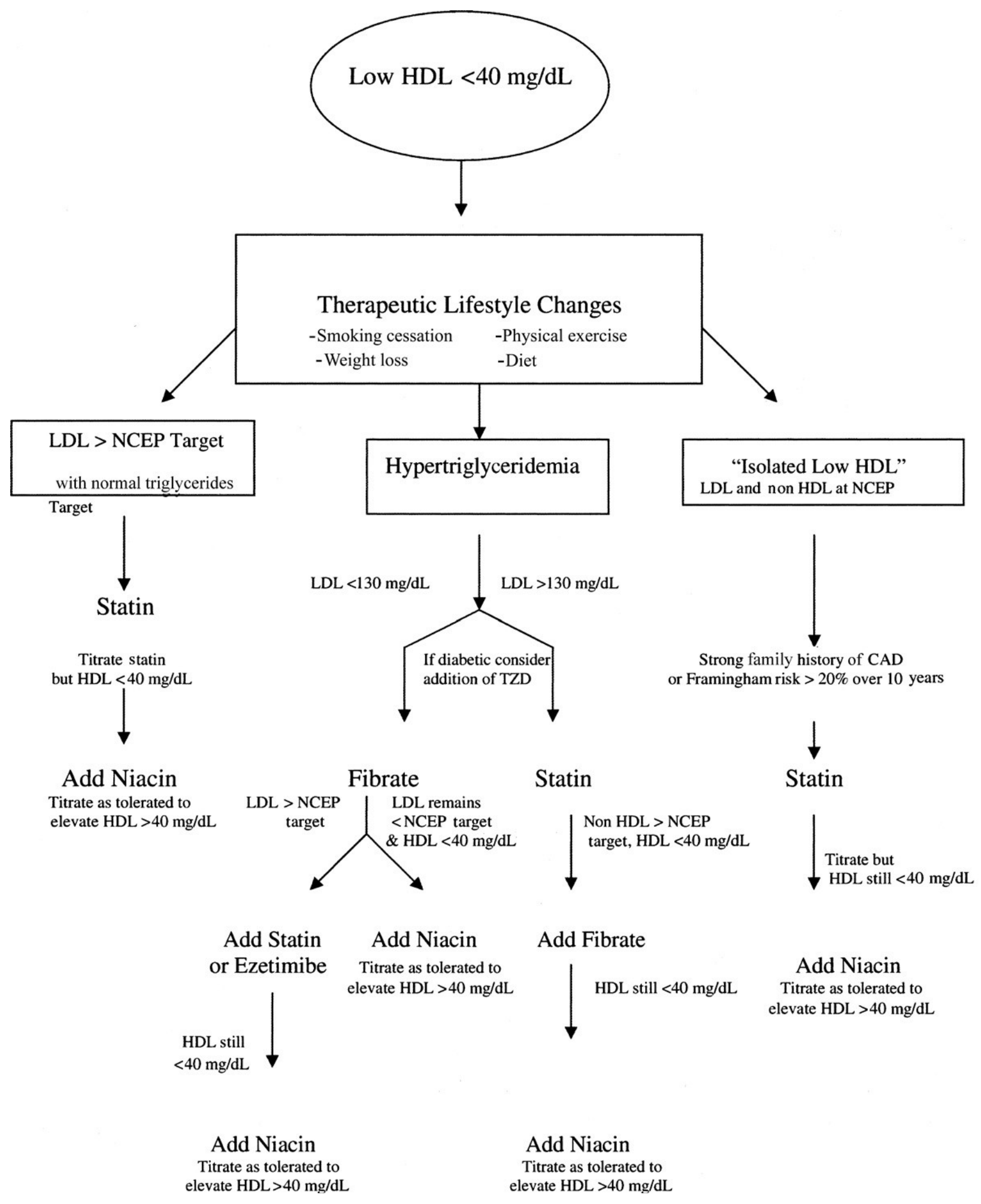

Figure 2. Algorithm for the management of low serum high-density lipoprotein (HDL) cholesterol. CAD - coronary artery disease; LDL - low-density 
lipoprotein; NCEP - National Cholesterol Education Program; TZD -thiazolidinedione. (Adapted from Circulation.22) 